Hum. Hered. 1988;38:64

\title{
Decade of the Tropics
}

\section{Call for Participants}

The 'Decade of the Tropics', an international research programme under the auspices of the International Union of Biological Sciences, has a section devoted to human biological problems. The principal topics are (1) human working capacity, and (2) human genetic variation. Measurement of these, and investigation of factors affecting them in the tropics, are eligible for inclusion. Any units or investigators wishing to join in the programme should register their investigation, sending a short paragraph stating the aim and location of their researches to the Secretary, International Union of Biological Sciences, 51 Boulevard de Montmorency, 75016 Paris (France). Further details are available in Biology International, No. 14, December 1986. 